\title{
On the Historical Development of Confucianists' Moral Ideas and Moral Education
}

\author{
Shaogang Yang (Guangdong University of Foreign Studies)
}

The Chinese ancient Confucian school was founded by Confucius in the Pre-qin Dynasty more than 2,500 years ago, whose moral and ethical thoughts have become a theoretical system of moral norms centered on "the benevolence." With its continuous development and completion in so many years, the Confucian moral ethics has become a kind of moral and cultural tradition with the Chinese characteristics, and has formed a "basic morality" or "mother morality" that is accepted by most Chinese people and even by people in Asian regions. Up to now, the Confucian thought has more and more important influences in the present world, because it embodies a kind of moral culture and spirit with a thorough knowledge of human thoughts and theoretical integration, and therefore, it is linked together to some extent with the moral tradition in our Asian and Pacific regions. We could also say that the Confucian ethics not only belong to China, but also belong to the world.

\section{The Confucian Morality - Its Own Colors in the Contention of a Hundred Schools of Thought}

The radical social changes in the Spring and Autumn Period (770-476 BC) as well as the Period of Warring States (475-221 BC) caused the contention of all schools of ancient Chinese thoughts in the pre-Qin period, during which there were many different schools such as Confucianism, Daoism, Mohism, Legalism, Military Strategism, Farmerism, Logicians and the Eclectics that elaborated abundant thoughts of morality in their own right. The Confucianism, Mohism, Daoism and Legalism had the most significant influence among them. People might ask, however, why this competitive situation has not existed in Chinese society and become the traditional characteristics of the Chinese culture for the social democracy, and why the Confucianism could become one of the most important moral pillars that has governed the Chinese society for more than 2000 years since the Han Dynasty (206 BC - AD 220). Through the historical analysis of the formation and development of the Confucianist moral ideas, it could be easily found that an inner connection existed between Confucius ideology of morality and the inner requirements of pursuing goodness in human mind, and then it could be gradually accepted by the people in the world. 
Confucius was the earliest to use the concept of "Ru" (moral scholar) and made the scholars become Confucianists, for Confucius said to his student Zi Xia: "You should try to be a scholar of both great ability and moral integrity, not to be an egoistic and ignorant one." (Confucius 1998, 77).

Looking back to his family devoted to literature for generations, Confucius' ancestors from Shang Dynasty (16 $6^{\text {th }}-11^{\text {th }}$ century BC) to Zhou Dynasty ( $11^{\text {th }}$ century to $256 \mathrm{BC}$ ) were some kinds of scholars, and even Confucius said about himself, "I was born in an impoverished family and therefore I have learned quite a number of practical skills belonging to the lower stratum in the society." (cf., 119). It is clear that Confucius was also a common scholar when he was young, but he was not satisfied with his position and was determined to realize his great ideals of managing state affairs with his profound erudition and lofty aspirations. And thereupon, in the flower of his age he began to run a private school and go about selling his ideas and the Confucian school was formed gradually. Just as the Jungian scholar Erich Neumann said, "One must first of all solve his own basic problems of morality and then he could play a responsible role in the collective." (Neumann 1998, 11). This was a significant change which was realized by Confucius through his own cultivation of morality for many years. First, the change of its mission and identification: It made the common skilled scholars become chivalrous scholars who could "worship and follow the example of ancient sages Yao and Shun's theory or conduct, and establish the rules to govern the officials and the nations." Its mission was to "positively intervene the political affairs, and give guidance to the land under heaven." Second, the change of its action way and the forms of survival: It inherited and developed the ancient six skills so that the scholars was no longer to do the ritual work when a family gives birth to a child or a family has someone died, but become a kind of gentleman to establish themselves in society with their moral articles. And the third is the change of its historical position. Confucius advocated a series of systematic social ideas and values that had become one of the most influential moral values during the pre-Qin period.

The contents of Confucius' ideology are very rich and I could only simply explain the core implications of his moral ideas here in this article.

1. Benevolence and loyalty were the highest principle of Confucianism. Confucianism started from advocating the idea that "deny self and return to propriety," and thus it regarded the authenticity and tolerance in the human relationship as the basic ritual requirements and the norms of moral cultivation. For example, what Zengzi said: "Everyday I make several selfexaminations on the following points: whether I have or not exerted my utmost in helping others; Whether I have or not been honest and sincere in intercourse with friends; whether I have or not practiced the instructions of my teacher" (Confucius 1998, 3) embodied the meaning of authenticity, and what Confucius said in the Doctrine of the Mean "One nears the doctrine of the 
mean when he is faithful to and considerate of others. What you would not have others do unto you should not be done unto them." (cf., 13) reflected the Confucian "tolerance."

2. The distinction between justice and benefit is Confucianists' standards of moral assessment. Confucius regarded an individual's pursuit for justice or benefit as the principle to distinguish rightness from wrongness, for his words "The superior man understands what is moral; the inferior man understands only what is profitable" (cf., 49), distinctively reflected one's lofty pursuit of the moral spirit. Of course, what Confucius opposed was an unprincipled seeking for the benefits without justice, but not the necessary pursuit for the material benefit. He clearly pointed out: "Riches and honor are what every man desires; but if they can be obtained only by transgressing the right way, a virtuous man will disdain to hold them. Poverty and lowliness are what every man detests; but if they can be avoided only by transgressing the right way, a virtuous man will not try to evade them." (cf., 43-45). And therefore a gentleman should consider moral principles while facing profit. It is revealed that Confucius admitted both the good and evil in human nature, when an individual confront a dilemma choice of good and evil, Confucius emphasized that he should get the benefit based on the justice.

3. Intelligence, benevolence and braveness are Confucianists' basic virtues. Just like the ancient Greek scholar Aristotle, Confucius also defined three kinds of virtues a moral person should have. He said that as a gentleman, "the wise man can hardly have perplexities, the humane can hardly be sorrowful, and the brave can hardly be fearful" (cf., 131). Of course, it is not easy for an individual to have all the three virtues at the same time in his real life, but as the universal moralities that all human beings have, the three virtues are the most ideal personality traits abstracted from human virtues. They are both unified whole and have some interaction. What we should specially noted is that such ideal personality that all human beings have in common is consistent with everyone's inner requirements. Since the three virtues are a gentleman's morality, and gentlemen concentrated embody the human beings' virtues "which are generally consistent and repeatedly evoked," then these virtues are truly the inner pursuit of all human beings to some extent. Confucius had also elaborated the relationship among the three virtues, and to him the intelligent is the prerequisite to the benevolence, and the benevolence is the center of the intelligence, and the brave is the outward behavior of both intelligence and benevolence. What Confucius said "The humane feel relieved in carrying out humanity, while the wise find it beneficial to practice humanity" (cf., 43) expounded the different functions of intelligence and benevolence. His idea that "If a man does not insist on such an environment in selecting his residence, how can he be counted as being wise" (cf., 43) clarified that benevolence is the premise and the goal of cleverness. He also showed that the brave courage is the expression of benevolence and 
brightness with the word that "Man of lofty ideals and moral integrity will under no circumstance seek life at the expense of the principles of humanity. On occasion they will be brave enough to sacrifice their lives to accomplish the cultivation of the quality of humanity." (cf., 239). In fact, Confucius further developed the idea of modest gentleman advocated by I Ching (classic work of ancient Chinese Daoism), and made the three virtues the necessary requirements of Confucian moral cultivation.

\section{The Moral Ideas in the Han Dynasty That Restrained All the Other Schools But Only Respected Confucianism}

When the First Emperor of Qin (259-210 BC) unified China in 221 BC, he implemented the cruel legal policy in order to maintain and consolidate his dominant position. This had something to do with the tradition of the Qin Nation during the Warring State Period in which it advocated a national policy of running the country according to laws so as to realize the purpose of making the country rich and its military force efficient. For instance, before the First Emperor of Qin unified China, the Qin nation accepted Shang Yang's idea to carry out the Constitutional Reform for more than 10 years, and as a result "the Qin people felt very pleased to find that no one would pick up the things that others lost in the street into his own pocket, there were no thieves and brigands, houses had adequate supplies and people live in contentment, people were brave enough to fight for their own country but not for the private struggle and the country was run quite well." (Sun \& Li 1997, 198). It had great impact on the society of the Qin nation. The Legalist Han Fei's thought, who was a main representative of Legalists during the pre-Qin Period, and who had lived in the Qin nation as a guest for a period of time, had also greatly influenced the dominant ideas and policies of the Qin nation. Up to the time of $34^{\text {th }}$ and $35^{\text {th }}$ year of the First Emperor of Qin, with the implement of such policies as prohibiting the private schools, burning books and burying Confucian scholars alive, and "treating the laws as the teaching contents and the officials as the teachers", the thought of rule by law in the Qin Dynasty arrived its peak, and also meant that the feudalist and autocratic government of the First Emperor would begin to go downwards. And finally the Qin Dynasty was overthrown by the peasant uprising. Because, as we know, the legal rules are only the outside heteronomy and repression that could only make the evils in the human nature to hide into the unconsciousness temporarily. Only when the moral forces are made use of, can the longstanding function of the moral autonomy be displayed.

The failure of the policy that ruled the country by law in Qin dynasty caused the rulers' sharp vigilance in Han Dynasty (206 BC - AD 220). In order to maintain its dominance of "ruling all the land" more permanently, the rulers in the Han Dynasty adopted the policies that were relatively more open to 
every schools and thoughts, and therefore, at the beginning of the Han Dynasty, a new situation that all schools of thoughts contended for attention appeared. Through decades of restoration, up to the year $140 \mathrm{BC}$ when the emperor Han Wu Di ascended there appeared a prosperous social situation that the politics was stable and economics was developed. The emperor Han Wu Di adopted the great Confucianist's Dong Zhongshu suggestion that "restrained all the other schools of thought" and "only worship the Confucianism," and defined Confucianism that holds humanity, justice and morality in esteem as the orthodox political guiding thought so that the dominant position of Confucianism was established in Chinese society.

Dong Zhongshu's thought raised a systematic ideology of rule by virtue through earnest teachings, which was composed mainly of Confucius and Mencius thoughts in the pre-Qin Dynasty, assimilated the theories from Daoism, Legalism and yin-yang and five elements, and also made use of the teleology thought of theology. He said: "If a king wants to make great achievement, he'd better resort his beginning to the heaven. The most important of all for the manifestation of God's will depends on yin and yang. The latter is morality, and the former is penal code. The main function of the penal code is to rule the country through killing, and the main function of morality is to advocate a moral life... And so it could be seen that the heaven attempts to rule by morality, but not by penal code." (Ban 1962, 16). Here Dong Zhongshu deduced the way of human life from the God's will, and regarded the policy of benevolence and rule of virtue as the fundamental principles of kingly way. The Three Cardinal Guides (ruler guides subject, father guides son and husband guides wife) and Five Constant Virtues (benevolence, righteousness, propriety, knowledge and sincerity) that he produced had become the central contents of the traditional moral education in Chinese society since the Han Dynasty, and many of his moral ideas such as "value justice above material gains," "appease public feeling with benevolence and straight oneself with justice," "one must be both benevolent and knowledgeable" had become the basic principles and methods of an individual's moral cultivation. It is just because of the instructional function of Confucianism in maintaining the feudal dominance that the rulers in Han Dynasty and nearly all the latter dynasties vigorously advertise Confucianist thoughts. Thus, in the feudalist ages, all the emperors and officials as well as the common people had to learn and practice the moral ideas of Confucianism so as to follow the moral obligations and preaching through the understanding of the relation between "the Way of Heaven" and "the way of human life," in this way the purpose of ruling the country "by taking hold of the key link and strictly adhering the teachings" could be arrived.

The excessive admiration for Confucianism, however, caused the unified centralization of state power and therefore the apposed ideas could not be expressed properly. Just as Neumann (cf., 1998) said, "The monism 
tried to abolish the opposite principle of moral problems among groups and raised one pole of the two onto the absolutely high position." (p. 67). Similar to the emphasis on rule by law, this monism also locked the dark and shadow out of the door and would still fall into the conscious crisis of avoiding evils. The severe turbulence of the Chinese society since the end of the Han Dynasty for several hundred years was the reflection of the crisis.

\section{The Moral Culture of Incorporating Things of Diverse Nature with Unity of Opposites}

From the end of the Han Dynasty through the Three Kingdoms, Wei, Jin, the Northern and Southern Dynasties, the Chinese society was in troubled times that the country was split and the society was in turmoil, and the dominant position of Confucianism was criticized seriously. With the economic transformation, national amalgamation, cultural exchange and educational reform, there appeared a metaphysical sect that adapted to the ruling need of the family of power and influence, that maintained to use Daoism with I Ching, Lao Zi and Zhuang Zi to reconstruct and explain Confucianism, and therefore a cultural trend in moral ideas which went from opposition to confluence made its way out.

The main representatives of the metaphysical thought at that time were Liu Shao, He Yan, Wang Bi, Ji Kang, Xiang Xiu, Guo Xiang and so on, who proposed their own ideas of moral psychology separately according to the moral requirements for various kinds of qualified personnel at the time. For example, Liu Shao was not only aware of the individual differences existing among people's minds in temperament and characters, but also explained the personality psychology of an individual in forming his morality. "A talented person treats morality as his goal. A moral person has more valuable qualities. And thus a person with morality would go along the way of mean. The socalled doctrine of the mean is the goal of the sages." (Liu 2009, 18). The doctrine of the mean here referred to the harmonious development of the moral contents with the Confucian tradition such as "humanity, justice, propriety, wisdom and sincerity". He also said: "The moral person is usually wise and ordinary, who can share all the talents of others but not sing his own praise." (Liu 2009, 39). It is clear that Liu Shao's metaphysics both held the sages' moral intelligence in esteem and shared the ideological color of Daoism that governs by doing nothing that goes against nature.

Wang Bi analyzed the consistence and difference of natural instincts of human beings, and he pointed out that if human nature "is completely the same, the so-called similarity would not exist; if it is completely different, the so-called similarity would not exist, too. What I say the similarity means that people have something in common and have something different. The common point is that human nature is not good and evil, and the different 
point is that people have thick or thin inherited nature. Although they have some differences but they are not far from each other, they have what I say the similarity." (Wang 1980, 632). Wang Bi saw the difference between the thick and thin in the inborn factors of human inheritance, and realized the difference of good and evil in human nature, and this is quite valuable psychological thought of morality. He also used Daoism to explain the acquirement of morality and thus he thought, "Morality is something gained... How could one acquire morality? It is just through the way of life (Daoism)," because "The Heaven refers to the Dao. If one shares the morality with the Heaven, his way of life can run in both directions and even arrive at the pole of nothingness." (cf., 358). This sort of universe ontology based on nothingness constitutes the foundation of moral psychology in the metaphysical thought.

Although the metaphysics had very important social influences at that time, and there appeared the phenomenon with multiple cultures and various ideas co existing, the Confucian theory was still the dominant thought as a mainstream. Of course it had to make self-regulation continuously with the development of the ages. The Confucianists such as Fu Xuan, Liu Xie, Liu Zhou and Yan Zhitui were the main representatives of the time. For instance, Fu Xuan raised the point of view of ideal moral education with morality and orthodox gathering together, and he thought: "A man with an upright heart must have an upright morality. Using the upright morality to teach people is like setting up a good example, the common people will follow it without being ordered." (Liu 2010, 253). The so-called "upright morality" is actually the moral norms of "humanity, justice, propriety, wisdom and sincerity" that Confucianism always advocated, in which "justice" is the most important content of the Confucian ideal morality. According to the characteristics of the tome, Liu Zhou elaborated the methods and principles of individual moral cultivation such as "cultivate one's moral character along the moral course," "guard against the fullest extent and be cautious in wording" and "check erroneous ideas at the outset." Yan Zhitui carried forward the moral thought of Confucianism and raised the moral opinion centered on "the filial piety." He definitely pointed out: "The filial piety is the first of everything and is specially necessary to be learned and cultivated. There is nothing more important than this!" (Yu 2004, Vol. 3). His well-known works The Family Advice has become one of the classic books of the traditional Chinese family moral education.

Besides the moral psychology of Confucianism and Daoism, the moral values of Buddhism gradually became an important tradition of the Chinese moral culture. From the Wei Dynasty (386-532) to the Sui and Tang Dynasty (618-907), the translation levels of Buddhist Scriptures in China raised very quickly, more and more Buddhist theorists headed by the Chinese scholars began to play their roles. Especially during the time of Sui Dynasty and Tang Dynasty, Buddhism became a state religion for a time. Its moral values had also transformed gradually from the outward striving for Buddhism of the 
traditional religious doctrine to seeking the release of mind through the inner self-regulation. Jung's opinions about the psychological crisis in middle ages are the Western expression of Buddhism from outward to inward exploration. In China, from the well-known Buddhist Hui Yuan in the East Jin Dynasty to the religious sect of Tiantai and Zen in Sui and Tang Dynasties, they all embodied the inheritance and transformation of the Buddhist values. In sum, during the development of the feudal society in this period of nearly 1,000 years, the Chinese moral psychology had been evolved and changed significantly, and the contention of thought mainly among Confucianism, Daoism and Buddhism, and the situation of both opposite and confluence had been formed. They assimilated each other and drew lessons from one another, they absorbed everything and anything and compromised each other, so that the traditional Chinese ancient moral ideas became more and more complete.

\section{The Moral Rationality of Surviving the Heavenly Principle and Abolishing Human Desire}

With the development of the feudal society, the confluence of Confucianism, Daoism and Buddhism caused the appearance of the Confucian school of idealist philosophy of the Song (960-1279) and Ming (1368-1644) Dynasties, and therefore in moral thought arose the characteristic of mixing all those values together. The early representatives of the school in the early Song Dynasty were Hu Yuan, Sun Fu and Shi Jie. For instance, the moral education advocated by $\mathrm{Hu}$ Yuan emphasized the personality change by practicing what one preaches as he said: "A teacher who initiates right knowledge should practice it first." The suggestions proposed by Shi Jie such as "Writings are for conveying truth" and "The purpose of teaching is to propagate doctrines of the ancient sages" provided moral education with the teleology and established the foundation of getting on in life for moral cultivation. Sima Guang further developed such philosophy proposed in the early Song Dynasty and made a systematic elaboration of the three basic processes of moral cultivation that included strict enforcement, moral cultivation and becoming a moral person. He maintained that such ideas as "resisting outside influence" and "not just do good things consciously" could be used to explain the study of the phenomenon of nature, and he also advocated that one's goodness should be a kind of moral state with high self-discipline. These ideas had great impact on the restraining of human desire proposed by the later idealist philosophers.

Later on Zhou Dunyi and Zhang Zai carried forward and further developed the early idealist philosophy and built an important ground for the construction of the latter system of morality. For example, Zhou Dunyi emphasized that moral education was the pursuit of "the sages" personality and aimed at "making a moral person." The foundation of such personality was "the sincere," however, that had transcended the sincere proposed by 
Confucian tradition in The Doctrine of the Mean. "The origin of the universe and everything comes from the sincere. No matter how the heaven and earth changes, if it goes along the right way, the sincere would be established," Zhou Dunyi (Huang \& Yu 2000, 89) claimed. It is evident that "the sincere" here is a requirement of moral metaphysics that demands a person to be selfless and let things to take their own course. To arrive at such sincere state, one had to use the methods of moral cultivation such as "mainly be quiet and be cautious of action", "resist desire" and "be good at learning" to form his own moral character. This kind of moral idea became one of the origins of thoughts that were stressed by the idealist philosophy such as "honest and sincere," "be quiet" and "restrain one's selfishness." It is something like what Jung pointed out, "Good and evil are principles of our ethical judgment, but, reduced to their ontological roots, they are 'beginnings,' aspects of God, names for God." (Jung 1964, 458). Only when a person trusts the significance of the holy sincerity and "lets he himself overwhelmed by it," could he be a truly moral person.

Of the four schools of the idealist philosophy, the position of Cheng Yi and Cheng Hao is a little bit lower than that of Zhou Dunyi and Zhang Zai, but their moral ideas further enriched the content of the idealist philosophy. They accepted the theory of original goodness of human nature, but according to them, the "goodness" is actually the combination of "nature" and "Dao," that is, "Dao is the nature. If one wants to seek the nature outside the Dao, or seek the Dao outside the nature, it can never be done." (Cheng 1981, 1). The unification of "human nature" and the "Dao" provided the traditional theory with the logically theoretical bases, and also provided the individual moral development with the basis of idealist philosophy. The two Cheng's thought that although all the human nature is originally good, the moral values expressed through one's behavior are quite different because people may have different moral judgment of their own conducts, and thus "When the vital energy is clear, one's ability appears good; when the vital energy is chaotic, his ability looks evil. The man who is born with the clear vital energy is a sage, and the man who is born with the chaotic vital energy is a fool." (cf., 291). In other words, a sage is a person who is born with knowledge; a person of virtue is a person who has knowledge through learning; an ordinary person is one who is difficult to acquire knowledge, and a fool person is one who is backward and has no urge to make progress. And then, what moral education aims at is not to change one's human nature, but change the ability that makes human nature play its role. Referring to this idealist philosophy, Cheng proposed two principles of moral education that demand to "survive the heavenly principle and to abolish the human desire," so as to make moral psychology be connected with ontology and epistemology. They defined the standards of moral values as the one that conform to the "heavenly principle," but not originated from "human desire." In the real life, however, there always exists the opposite and conflict between "the heavenly principle" and "the 
human desire," so, moral education must regard the personality of a "sage" as a standard to make moral judgment. When such personality embodies in one's inner mind, it is a situation of moral completion, the main characteristics of which are "restraining one's selfishness," "be respectful," and "be honest and sincere." Even the Western scholar Carl Gustav Jung evidently agreed with the moral attitude of the Orient, for he said, "Anyone who perceives his shadow and his light simultaneously see himself from two sides and thus gets in the middle." (Jung 1964, 463). With this moral philosophy in one's mind, all of his conducts would acquire moral values.

The great Confucianist Zhu Xi in the Southern Song period made the idealist philosophy reach the highest peak in the history. He regarded "the understanding of human relations" as the goal of moral education, that is, only through recognizing and practicing the feudal morality centered on "the Three Cardinal Guides and Five Constant Virtues," can a man be cultivated into a person who could obey the feudal ethics of his own free will. "The understanding of human relations," however, could not be limited in this, its final purpose is to raise the personality of sages and men of virtue like Confucius and Yan Hui who took delight in doing something moral, and the sages' spirit that is the expression which conforms to human beings' inner cultivation and spiritual state. To realize such personality, two forms of moral cultivation were needed, that is, moral cognition and moral practice. An intimate relationship exists between the two. As Zhu Xi (1983) clearly pointed out: "Cognition and practice are always accompanied. It is something like the relation between eyes and feet, without feet, eyes cannot walk, and without eyes, feet cannot look. As for the time order, knowledge is the first, and as for the importance, behavior is more valuable." (cf., Vol. 33). It is clear that on the sequence of moral development, Zhu Xi maintained that "cognition is earlier than practice," and then according to this characteristic, he defined the basic sequence of moral cultivation, that is: "knowledge, examination, cautious consideration, clear distinction and practice persistently," and he further proposed the principles of moral cultivation: "having both extensive learning and intensive knowledge, accumulating and making progress step by step; daily expenses should be geared to oneself, and reviewing the past helps one to understand the present." (cf., Vol. 64).

And therefore a speculative theoretical system of Confucian moral philosophy of idealism was formed.

Up to the beginning of the Ming Dynasty, the dominant position of the two Chengs and Zhu Xi's idealist philosophy had been established, because its function in maintaining the feudal government was much greater than the traditional Confucianism, even though it stemmed from the theory. The great philosopher like Zhu Xi appeared in the Southern Song Dynasty, but the rulers then did not pay much attention to his thought, and sometimes even called it "pseudo learning." It was only up to the period of Yuan Dynasty, when Zhu Xi's 
works Notes on the Four Books became one of the standard textbooks of the imperial competitive examination. And it was only during the Ming Dynasty when the books such as The Collected Works of the Four Books, The Collected Works of the Five Classics and The Collected Works of the Principles of Human Nature were revised, that the dominant position of the idealist philosophy had been established. During this period of time, the idealist philosopher Xue Xuan further developed Zhu Xi's thought, and proposed the principles of, oral cultivation "The true acquirement of morality depends on the real practice" and "On one hand one must know the ways of the world, on the other hand one should know the course of nature," and so as to emphasize the role of moral practice. Another idealist philosopher Wu Yubi combined Zhu Xi's idealism and Lu Jiuyuan's philosophy of the mind, and summed up all the Confucianism from the pre-Qin period to the Song Dynasty as the great learning of sages and men of virtue that "survive the Heavenly principle and abolish the human desire" in order to "become sages and men of virtue through learning." He thought: "There is no other way of learning from the sages and men of virtue, it only relies on oneself," and therefore, "If you want to acquire the learning of sages and men of virtue, you should study hard, by deeply exploring the articles and turning morality over in your mind." (Wu 1987, 360). It is clear that such ways of moral cultivation is a special combination of the idealist philosophy and the philosophy of mind.

\section{The Moral Criticism Fighting Against the Feudal Code of} Ethics and Pursuing Justice, and Human Nature

During the end of Ming Dynasty and the beginning of the Qing Dynasty (16441911), the social and class contradictions became more and more sharp. With the cultural and economic infiltration of the Western societies, the Western social and natural sciences also came into China. Under such complicated historical condition, the traditional moral ideas of ancient China began to be challenged seriously. A number of progressive thinkers such as Li Zhi, Huang Zongxi, Gu Yanwu and Yan Yuan, accepted some of the Western learning to some extent, and criticized the Confucianism headed by the idealist philosophy of the two Cheng's and Zhu Xi's, and strongly pounded at the dominant position of the classic Confucianism that had governed Chinese society for 2000 years.

On moral ethics, they unified morality and utility, and combined the heavenly principles and human desires. According to Li Zhi, "If a man wants to acquire justice, he had to get some material gains. If it is not for this purpose, that is not the real justice," because "having one's meals and clothes is the innate laws of human relations, without which there will be no ethical things." On the question of habitual nature, Wang Fuzhi didn't agree with the opinion of "habitual nature is born good," and thought that the habits and 
characteristics “could be formed if they haven't been built, and could be abolished if they have been formed." On the relationship between the heavenly principle and human nature, Wang Fuzhi emphasized the role of the principle in restraining the desire while maintaining that "the desire could produce the heavenly principles," because the desire would be spread unchecked without the principles, and there will be useless without desire," Therefore it should be "let nature take its course" so that the principles and desires will not "contrary to each other, the two will be combined and as the system mutually." (Wang $1988,826)$. In this way the purpose of arriving at the great harmony of human nature and heavenly principle could be realized. In the later period Dai Zhen directed the spearhead of criticism to the theory of inborn morality of the idealist philosophy, and thus emphasized that "Dao is the common practice of human relationships." Here there is the distinction between the heavenly principle and humanity, the former is the reason of everything in the world and the latter is the reason of human beings. As for the reason of humanity, there is nothing but let human relations and daily functions take their own courses.

It is evident that all these ideas heavily stroke the traditional Confucianism, especially the moral "authority" in the idealist philosophy that upheld "the sages" and "the heavenly principles," through which moral education transformed from the learning of sages to the learning of human relations and daily functions, and there appeared a tendency of thought that restores its historical truth. This is just something like what Jung said, "I can master their polarity only by freeing myself from them by contemplating both, and so reaching a middle position. Only there am I no longer at the mercy of the opposites." (cf., 464). The two sides here refer to the contradiction of the dark and bright, and it could also be understood as the opposition between the learning of sages and the learning of human relations. They are in fact the two aspects of one unity. The true moral education should be the right explanation of the opposed double aspects because moral personality is enhanced in the right differentiation and analysis of these opposed two aspects.

\section{Literature}

Ban, G. 1962. Books of Han Dynasty: The Biography of Dong Zhongshu. Beijing: Publishing House of China.

Cheng, H. 1981. The Posthumous Papers, Vol. 1. Works of Cheng Yi and Cheng Hao. Beijing: The Chinese Books Press.

Confucius. 1998. The Analects of Confucius. Jinan: Shandong Friendship Press.

Huang, M. \& Yu, S. 2000. Chinese History of Educational Philosophy. Jinan: Shandong Education Press.

Jung, C.G. 1964. Good and Evil in Analytical Psychology. Collected Works of C. G. Jung. Vol. 10. New York: Bollingen Foundation. 
Liu, S. 2009 a. Biographical Notes and Data: Jiu Zheng. Wuhan: Wuhan Press. Liu, S. 2009 b. Biographical Notes and Data: Liu Ye. Wuhan: Wuhan Press.

Liu, Z. 2010. Fu Tsu: An Explanation. Tianjin: Tianjin Ancient Books Publisher.

Neumann, E. 1998. Depth Psychology and a New Ethic. Trans. Gao Xiantian \& Huang Shuiqi. Beijing: Eastern Publisher.

Sun, P. \& Li, G. 1997. The Chinese History of Educational Thought. Shanghai: East China Normal University Press.

Wang, B. 1998. „Explanations of Lao Tzu's Dao De Jing”. In: The Integrations of Ancient Scholars. Chengdu: Sichuang People's Publisher.

Wang, F. 1988. Collected Works of Chuan Shan. Changsha: Publishing House of Yuelu.

Wu, Y. 1987. „Kang Zhai Set”. In: Complete Collection of Four Treasuries. Shanghai: Shanghai Ancient Books Press.

Yu, Z. 2004. The Family Advice. Guangzhou: Guangzhou Publisher.

Zhu, X. 1983. Notes on the Four Ancient and Famous Books. Vol. 2. Beijing: Publishing House of China. 


\title{
On the Historical Development of Confucianists' Moral Ideas and Moral Education
}

\begin{abstract}
The Confucian ethics which is the main body of the Chinese traditional culture has established its "basic morality" or "mother morality" not only in China, but also in some of the Asian countries. It is formed in the long historical development of more than 2000 years. First of all, it had the contention of a hundred schools of thought in the Pre-Qin Dynasty, and the Confucianist thought with its own colors was formed at that time. When Dong Zhongshu made his suggestions that restrained all other schools but only respected Confucianism, the predominance of Confucianism over the political life had been defined in Chinese society. After the later generations' cooperating thing of diverse nature with unity of opposites, it was developed into the idealist philosophy of the Song (960 -1279) and Ming (1368-1644). Dynasties, which combined Confucianism, Buddhism and Daoism. The critical development of the modern Chinese society to Confucianist thought made us scholars have a timely reflection on the Confucian ethics. The requirement of constructing a harmonious world in the present time made us further considerate the moral education with Confucianist ethics.
\end{abstract}

Keywords: Confucianist ethics, basic morality, moral education in Asian and Pacific regions

Ethics in Progress (ISSN 2084-9257). Vol. 4 (2013). No. 1. 34-47. 